NBER WORKING PAPERS SERIES

\title{
IS THERE A CONFLICT BETWEEN EC ENLARGEMENT AND EUROPEAN MONETARY UNIFICATION?
}

Tamim Bayoumi

Barry Eichengreen

Working Paper No. 3950

\author{
NATIONAL BUREAU OF ECONOMIC RESEARCH \\ 1050 Massachusetts Avenue \\ Cambridge, MA 02138 \\ January 1992
}

This paper is part of NBER's research program in International studies. Any opinions expressed are those of the authors and not those of the National Bureau of Economic Research. 
NBER Working Paper \#3950

January 1992

\title{
IS THERE A CONFLICT BETWEEN EC ENLARGEMENT AND EUROPEAN MONETARY UNIFICATION?
}

\begin{abstract}
Recent proposals for enlarging the European Community to include the EFTA countries raise the question of whether the new members should participate in a European Monetary Union. In part, the issue hinges on the incidence of aggregate supply and demand disturbances. We use data on prices and output and a VAR decomposition to analyze this issue empirically, grouping economies according to the magnitude of the disturbances, their cross-country correlation, and speeds of response. This leads us to distinguish an EC "core" (made up of Germany and its immediate neighbors) and an EC periphery (made up of the UK and the Southern European members of the Community). Austria, Sweden and Switzerland behave more similarly to the EC core than do Norway, Finland and Iceland. This suggests that the case for EMU participation is stronger for Austria, Sweden and Switzerland than for the other EFTA countries.
\end{abstract}

Tamim Bayoumi Bank of England Threadneedle Street London EC2R $8 \mathrm{AH}$ England
Barry Eichengreen Department of Economics University of California Berkeley, CA 94720 and NBER 


\section{Introduction}

The European Community faces many bumps on the road to monetary unification. At the time of writing, debate centers on the degree of policy convergence that is a prerequisite for EMU. Germany and its Immediate neighbors, such as the Netherlands, insist that economic policieg must be closely harmonized before nationg form a monetary union. In contrast, the countries of Southern Europe, led by Italy, maintain that policy convergence can be deferred to the period following the trangition to EMU. This dispute has given rige proposals for a two-speed EMU, in which countries whose policies are already closely harmonized form a monetary union immediately, but the others initially remain outside.

If the problem were not already complicated enough, there is the isgue of EC enlargement. Austria's application for full EC membership, outstanding since 1988, has received a "fundamentally positive" evaluation from the EC Commissioner for External Affairs. ${ }^{2}$ Sweden applied for memberahip in July 1991, and its application has also been greeted favorably. Thus, the European Community will probably have at least two new members by $1995 .^{3}$ Finland is likely to submit its application in the epring of 1992, and Norway, Switzerland and Iceland cannot be far behind. ${ }^{4}$ The implicationg for EMU are far from clear. Does the prospect of EC enlargement strengthen the North's case for two-speed EMU or the South's argument for moving establish a single currency for the entire community? If the two-speed option is to be pursued, should the former EFTA countrieg

1 See for example Dornbusch (1990).

2 See Lodge (1991).

3 Economist Magazine (1991), p. 56.

4 Admittedly, Norway, Switzerland and Iceland remain deeply divided over the isgue. EC membership was the dominant isgue in Norway's September 1991 local electiong, in which the Center Party and Left Socialist Party, both anti-EC, scored significant gains. The position of the Nordic EFTA countries and of Iceland are discussed by hamilton (1990) and Gylfason (1990), reapectively. 
join at the first or second stage?

Discussion of this question should weigh the benefits of EMU membership against the costs. The benefits, about which we have little to say in this paper, take the form of the convenience and efficiency of transacting in one rather than several national currencies. The costs are associated with the need for the members of a monetary union to run identical monetary and similar figcal policies. ${ }^{5}$ The weight that should be attached to this imperative depends on, among other things, the incidence of shocks. If disturbances are distributed symetrically across countries, symmetrical policy responses will suffice. In response to a negative aggregate demand shock, for example, that is common to all EMU countries, a common policy response in the form of a simultaneous monetary and fiscal expansion would suffice. Only if disturbances are distributed asymmetrically across countries will there be occasion for an asymetric policy response and may the constraints of monetary union bind. 6

In a previous paper (Bayoumi and Eichengreen, 1991), we analyzed output and price data for EC member nations in order to extract information on aggregate supply and demand disturbances. We uged this information to. examine the correlation of disturbances across EC member countries, and compared that correlation with that exhibited by disturbances to different regions within an exigting monetary union (the United States). 7 In this paper we extend the analysig to the EFTA countries as a first step toward exploring the implications of EC enlargement for EMU.

5 The extent to which fiscal convergence ig a necessary corollary of monetary union remaing a debated point. See Eichengreen (1990a), Bayoumi and Russo (1991) and Goldstein and woglom (1991).

6 This point has been widely understood since the seminal work on the theory of optimum currency areas by Mundell (1961).

7 We found that aggregate gupply shocks to U.S. regions are smaller than shocks to EC countries, and that they are more closely correlated. our results also indicated that U.S. regions adjust to shocks more quickly than do EC countries, despite the lack of the exchange rate instrument, plausibly reflecting greater factor mobility in the U.S. than in Europe. These findings suggest that the EC may find it more difficult than the U.S. to run a monetary union. 
We use the structural vector autoregression approach to isolating disturbanceg developed by Blanchard and Quah (1989), who examined the timeBeries behavior of output and unemployment. But as in Bayoumi (1991), we instead use data on output and prices, which allows us to interpret the results in terms of the familiar aggregate-demand-aggregate-supply diagram. supply disturbances are distinguished from demand disturbances by imposing the identifying restriction that aggregate demand disturbances have only a temporary impact on output, while aggregate supply disturbances have a permanent effect (both have permanent effects on the level of prices). In addition to identifying the underlying disturbances, our methodology allowg us to look at the response to these disturbances, and hence allows us a measure of the speed of of the economy's adjustment to such shocks.

The remainder of this paper is organized as follows. Section II sets out the framework used to identify supply and demand disturbances. Section II describes our data and its properties, while section IV reportg the results of the statistical analysis. Section $v$ summarizes our findings and the light they shed on EC enlargment and EMU.

\section{Methodology}

Our methodological point of departure is the familiar aggregate demand and aggregate supply diagram, reproduced as the top panel in chart 1. The aggregate demand curve (labelled $A D$ ) is downward sloping in the price output plane, reflecting the fact that lower prices, by raising money balances, boost demand. The short run aggregate supply curve (SRAS) is upward sloping, reflecting the assumption that wages are sticky and hence that higher prices imply lower real wages. The long run supply curve (LRAS) is vertical, since real wages adjust to changes in prices in the long run. ${ }^{8}$

8 Although often thought of as a closed economy model, the analysis can be easily extended to include trade and the exchange rate. Textbook descriptions include Dornbusch and Fischer $(1986) \mathrm{Ch}$. 11, and Hall and Taylor (1988) Ch. 4-5. 


\section{Char I}

The Aggregate Demand and Supply Model

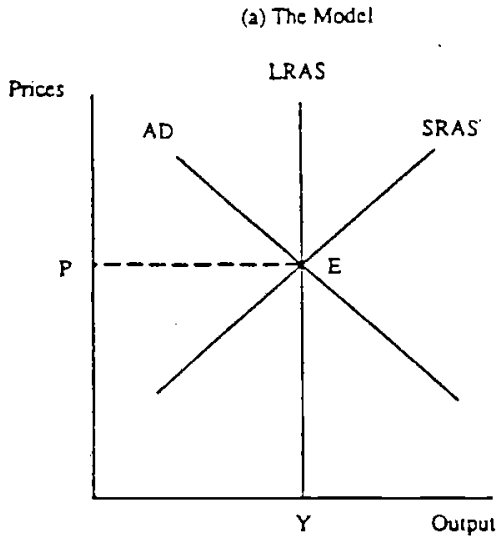

(b) A Demand Shock

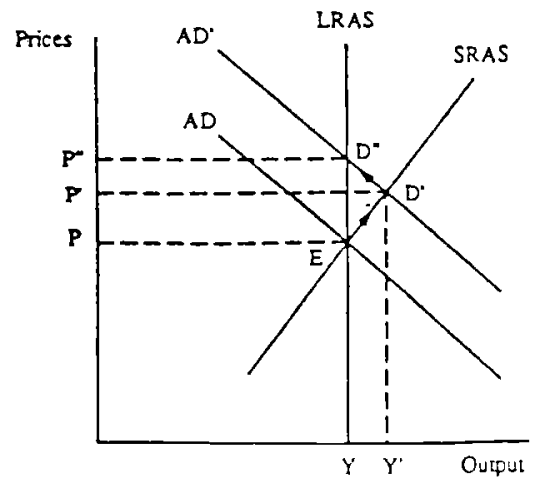

(c) A Supply Shock

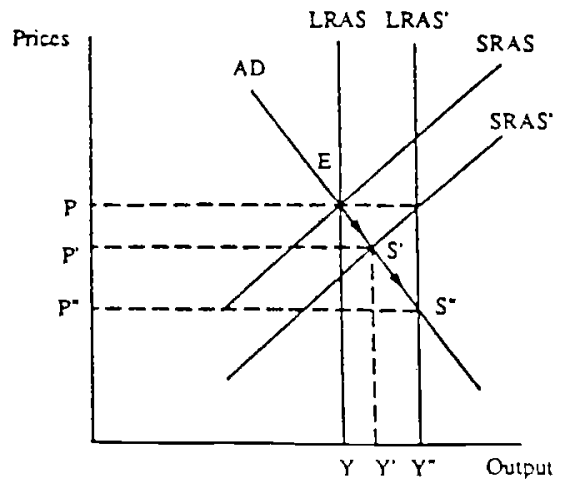


The effect of a shock to aggregate demand is shown in the left half of the lower panel. The aggregate demand curve shifts from $A D$ to $A D^{\prime}$, resulting in a move in the equilibrium from initial point $A$ to the new intersection with the short run curves, $D^{*}$. This raises both output and prices. As the aggregate supply curve becomes more vertical over time, the economy moves gradually from the short zun equilibrium $D^{*}$ to its new long run equilibrium, D''. This movement along the aggregate demand curve involves the return of output to its initial level, while the price level rises to a level which is permanently higher. (Depending on the price mechanism, there could be some cycling around the new long rum equilibrium,) Hence the response to a permanent (positive) demand shock is a short term rise in putput followed by a gradual return to its initial level, and a permanent rise in prices.

The effect of a supply shock is shown in the right-hand bottom panel of the chart. Assume that the long run level of potential output rises, say because of a favorable technology shock. The short- and long-run supply curves move rightwards by the same amount, as shown by SRAs' and LRAS'. The short run effect raises output and reduces prices, shifting the equilibrium from A to $\mathrm{S}^{\prime}$. As the supply curve becomes increasingly vertical over time, the economy moves from $S^{\prime}$ to $S^{\prime}$, implying further increases in output and reductions in prices. Unlike demand shocks, supply shocks result in permanent changes in output. In addition, demand and supply have therefore different effects on prices; positive demand shocks raise prices while positive supply shocks reduce them.

This framework is estimated using a procedure proposed by Blanchard and Quah (1989) for decomposing permanent and temporary shocks to a variable using a VAR, as extended by Bayoumi (1991). ${ }^{9}$ Consider a system where the true model can be represented by an infinite moving average

9 Quah (1991) discusses the issue of identifying restrictions for VARs. An important assumption which is required to ensure uniqueness of the decomposition is that the underlying series (growth and inflation in this case) are fundamental in a Wold sense, as pointed out by Lippi and Reichlin (1990). 
repregentation of a (vector) of variables, $x_{t}$, and an equal number of shocks, $\epsilon_{t}$. Formally, using the lag operator $L$, this can be written as:

$$
\begin{aligned}
X_{\mathrm{t}} & =A_{0} \epsilon_{\mathrm{t}}+A_{1} \epsilon_{\mathrm{t}-1}+A_{2} \epsilon_{\mathrm{t}-2}+A_{3} \epsilon_{\mathrm{t}-3} \cdots \\
& =\sum_{\mathrm{i}=0}^{\infty} L^{i} A_{\mathrm{i}} \epsilon_{\mathrm{t}}
\end{aligned}
$$

where the matrices $A_{i}$ represent the impulse responge functions of the shocks to the elements of $x$.

Specifically, let $x_{t}$ be made up of change in output and to the change in prices, and let $\epsilon_{t}$ be demand and supply shocks. Then the model becomes

$$
\left[\begin{array}{l}
\Delta y_{t} \\
\Delta p_{t}
\end{array}\right]=\sum_{i=0}^{\infty} L^{i}\left[\begin{array}{ll}
a_{11 i} & a_{12 i} \\
a_{21 i} & a_{22 i}
\end{array}\right]\left[\begin{array}{l}
\epsilon_{d t} \\
\epsilon_{s t}
\end{array}\right]
$$

where $y_{t}$ and $p_{t}$ represent the logarithm of output and prices, $\epsilon_{d t}$ and $\epsilon_{s t}$ are independent supply and demand shocks, and $a_{11}$ represents element $a_{11}$ in matrix $A_{i}$.

The framework implies that while supply shocks have permanent effects on the level of output, demand shocks only have temporary effects. (Both have permanent effects upon the level of prices.) since output is written in first difference form, this implies that the cumulative effect of demand shocks on the change in output $\left(\Delta y_{t}\right)$ must be zero. The model implies the restriction,

$$
\sum_{i=0}^{\infty} a_{11 i}=0
$$


The model defined by equations (2.2) and (2.3) can be estimated using a vector autoregression. Each element of $x_{t}$ can be regressed on lagged values of all the elements of $x$. Using $B$ to represent these estimated coefficients, the estimating equation becomes,

$$
\begin{aligned}
X_{t} & =B_{1} X_{t-1}+B_{2} X_{t-2}+\ldots+B_{n} X_{t-n}+e_{t} \\
& =(I-B(L))^{-1} e_{t} \\
& =\left(I+B(L)+B(L)^{2}+\ldots\right) e_{t} \\
& =e_{t}+D_{1} e_{t-1}+D_{2} e_{t-2}+D_{3} e_{t-3}+\ldots
\end{aligned}
$$

\begin{abstract}
where $e_{\text {t }}$ represents the residuals from the equations in the vector autoregression. In the case being considered, $e_{t}$ is comprised of the residuals of a regression of lagged values of $\Delta y_{t}$ and $\Delta p_{t}$ on current values of each in turn; these residuals are labeled $e_{y t}$ and $e_{p t}$, respectively.

To convert equation (2.4) into the model defined by equations (2.2) and $(2,3)$, the residuals from the VAR, $e_{t}$, must be transformed into demand and supply shocks, $\epsilon_{t^{*}}$. Writing $e_{t}=C \epsilon_{t^{\prime}}$, it is clear that, in the two-bytwo case considered, four restrictions are required to define the four elements of the matrix $c$. Two of these restrictions are simple normalizations, which define the variance of the shocks $\epsilon_{\mathrm{dt}}$ and $\epsilon_{\text {st }}$. A third restriction comes from assuming that demand and supply shocks are orthogonal. 10

The final restriction, which allows the matrix $\mathrm{C}$ to be uniquely
\end{abstract}

10 The conventional normalization is that the two variances are set equal to unity, which together with the assumption of orthogonality implies $C^{\prime} \mathrm{C}=\Sigma$. Where $\Sigma$ is the variance covariance matrix of the ghocks $e_{y}$ and $e_{0}$ However, when we wish to calculate the variance of the shocks themselves, $p$ we report results using the normalization $C^{\prime} C=\Gamma$, where $\Gamma$ is the correlation matrix of $e_{y}$ and $e_{p}$. These two normalizations gave almost identical paths for the shocks, except for a scaling factor, and hence are used interchangeably. 
defined, is that demand shocks have only temporary effects on output." As noted above, this implies equation (2.3). In terms of the VAR it implies,

$$
\sum_{i=0}^{\infty}\left[\begin{array}{ll}
d_{11 i} & d_{12 i} \\
d_{21 i} & d_{22 i}
\end{array}\right]\left[\begin{array}{ll}
c_{11} & c_{12} \\
c_{21} & c_{22}
\end{array}\right]=\left[\begin{array}{l}
0 . \\
.
\end{array}\right]
$$

This restriction allows the matrix $c$ to be uniquely defined and the demand and supply shocks to identified. ${ }^{12}$

Note that this restriction affects the response of output to the two shocks, but says nothing about their impact on prices. The aggregatedemand-aggregate-supply model implies that demand shocks should raise prices in both the short and long run, while supply shocks should lower prices. Since these responses are not imposed, they can be thought of as over-identifying restrictions ugeful for testing our interpretation of the resultg. ${ }^{13}$

\section{Data}

Annual data on real and nominal GDP spanning the period 1960-88 were collected from the OECD Annual National Accounts for each of the 12 members of the EC and for six EFTA members: Sweden, Switzerland, Austria, Finland,

\footnotetext{
${ }^{11}$ This is where our analysis, based on the work of Blanchard and Quah (1989), differs from other VAR models. The usual decomposition assumes that the variables in the VAR can be ordered such that all the effects which could be attributed to (say) either $a_{\text {, or }} b_{\text {, are attributed to }}$ whichever comes first in the ordering. This is achieved by a choleski decomposition (sims, 1980).

12 Note from equation (2.4) that the long run impact of the shocks on output and prices is equal to $(\mathrm{I}-\mathrm{B}(1))^{-1}$. The restriction that the long run effect of demand shocks on output is zero implies a simple linear restriction on the coefficients of this matrix.

${ }^{13} \mathrm{Blanchard}$ and Quah uge output and unemployment in their VAR, with the game identifying restrictions on the effect of shocks on output. Since unemployment would be expected to move in the same direction in response to both demand and supply shocks, their implied over-identifying restriction has less power than the one used in this paper.
} 
Norway and Iceland (data on Lichtenstein, the geventh member of EFTA, were unavailable). ${ }^{16}$ For each country growth and inflation were calculated as the first difference of the logarithm of real GDP and the implicit GDP deflator. The GDP defiator was used to measure prices since it reflectg the price of output rather than the price of congumption.

Chart 2 displays the standard deviations of inflation and GDP growth over the sample period for each of the countries. ${ }^{15}$ Countrieg located toward the bottom, left-hand corner of the box have relatively low output and inflation variability, and are therefore obvious candidates to join in a monetary union. In addition to Germany, which would undoubtedly form the focal point for any such union, the corner includes her EC neighbora, France, Belgium, the Netherlands and Denmark. It also contains several EFTA countriea, Austria, Sweden, Norway and, arguably, Switzerland.

Table 1 reports some sumary measures of the correlation across EC countries of inflation and output growth. As in our earlier paper, we divide the EC into a "core" comprised of Belgium, Denmark, France, Germany, the Netherlands and Luxembourg, and a "periphery" comprised of Ireland, Italy, Greece, Portugal, spain and the U.K. Table 1 reporta the share of the variance of output growth and inflation explained by the first principal component (the orthogonal component mogt correlated with the underlying series) for the two subgroups of EC countries and for the six EFTA memberg.

On the basis of the raw data, the EFTA countries look more like the EC periphery than the EC core. For the full period, the first principal

16 This same source provided an aggregate measure of output and price performance for the EC as a whole. Two different measures of the EC aggregate are available from the OECD, one based on conversiong of local currency data using 1985 dollars, and a second based on a weighting of EC real GDP and GDP deflator indices. Since the two data getg gave very aimilar results, only those based on 1985 dollar exchange rates are reported.

15 Iceland is excluded from the chart because the variance of both growth and inflation, at 0.042 and 0.131 , are so much larger than any of the other countries. 


\section{Chart 2 - Standard Deviations of \\ Inflation and Growth}

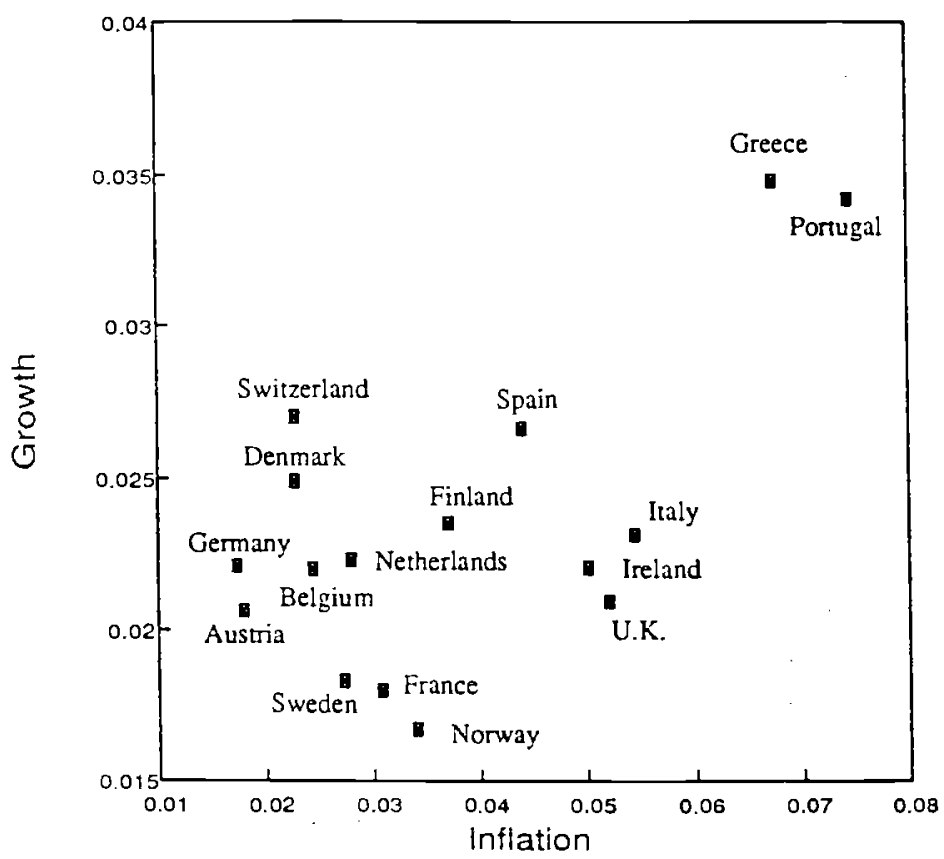


Table 1. Percentage of Variance Explained by the Firgt Principal Component Across Different Groups of Countries: Raw Data

\begin{tabular}{lccc}
\hline & EC Core & EC Periphery & EFTA \\
\hline & \multicolumn{3}{c}{ Growth } \\
Ful1 Period & 73 & 49 & 43 \\
$1963-71$ & 73 & 35 & 51 \\
$1972-79$ & 82 & 49 & 43 \\
$1980-88$ & 54 & 42 & 42 \\
& & & \\
Fu11 Period & & & 53 \\
$1963-71$ & 64 & 70 & 42 \\
$1972-79$ & 46 & 38 & 44 \\
$1980-88$ & 58 & 52 & 68 \\
& & & \\
\hline
\end{tabular}

Noteg: The EC core compriseg Germany, France, the Netherlands, Belgium, Denmark and Luxenburg. The EC periphery contains the UK, Italy, Spain, Portugal, Ireland and Greece. ErTA contains Switzerland, Austria, Sweden, Norway $F$ inland and Iceland. 
component explains glightly under half of the variance of output in both EFTA and the EC periphery, while almost three quarters of thig variance is explained in the case of the EC core. The regultg for inflation over the full period are more difficult to interpret. For the period as a whole, EFTA have the lowęst share of the variance in their inflation rates explained by the first principal component.

To illustrate trends over time, Table 1 also reports the percentage of the overall variance explained by the firgt principal component for three distinct time periods. For both the EC and EFTA the largest share of inflation is explained in the 1980s, presumably reflecting the extent to which price-level trends were dominated by disinflation after 1979 . In the case of output, for the EC countries the first principal component explains the largest share of the variance of output in the 1970s, the smallest share in the 1960s. The unusual coherence of output fluctuations in the $1970 s$ presumably reflects the fact that all countries experienced an unusually severe recession following the first oil shock. Interesting, this ig not the case for EFTA, perhaps because it includes an energy exporter (Norway) as well as net energy importers.

From these comparigong of the unprocessed data, it would appear that whatever criteria are used to determine whether the countries of the Ec periphery are included from the start in EMU should also be applied to the EFTA countries when they join the community.

\section{Regultg}

Bivariate VARs were egtimated for each EC and EFTA country in order to identify their aggregate demand and supply digturbances and associated impulse response functions. The number of lags was set to two in all the VARs since the schwartz Bayegian information criterion indicated that all 
of the models had an optimal lag length of either one or two. 16 A uniform lag of two wag chosen in order to preserve symmetry of specification acrosg countries. For all countries the eatimation period was 1963-88.17

In almogt every case the eatimation and simulation results accord with the aggregate-aupply-aggregate-demand framework discussed in section II. The "over-identifying restriction" that positive aggregate demand shocks ghould be associated with increases in prices while aggregate aupply ahocks should be associated with falls in prices was generally observed. In only two of the 18 cases considered here, namely Norway and Iceland, was it impossible to interpret the results using the aggregate-demandaggregate-supply framework.

By way of illustration, Chart 3 shows the impulse response functions for output and prices obtained from the EC aggregate data. These illustrate the identifying restriction. Positive demand shocks produce a temporary rise in output, which then gradually returns to its baseline level, while a positive supply shocks producea a steady rise in output to a new higher equilibrium level. Both aggregate supply and aggregate demand ahocks have long-run effects on the price level, with (positive) demand shocks producing a gradual rise in prices over time and aupply shocks producing a ateady decline in prices. This is exactly the pattern predicted by the aggregate-supply-aggregate-demand framework sketched above.

The estimated aggregate demand and aupply shocks for the EC aggregate are shown in chart 4. Large negative disturbances to supply are evident in

16 We algo estimated VARs with three lags because, in contrast to the schwartz Bayesian statistic, the Akaike information criterion showed the optimal lag to be above two in some models. This specification produced very similar results which consequently are not reported here.

17 Thia period includes an obvious change in regime, namely the breakup of the Bretton woods fixed-exchange-rate system in the early $1970 s$. chow tests for structural stability produced no evidence, however, of a structural break in the early 1970s. Limited analysis using data sets which excluded the Bretton Woods period produced similar results to thoae reported. 


\section{Chart 3 - Impulse Response Functions for the E.C. and U.S.}
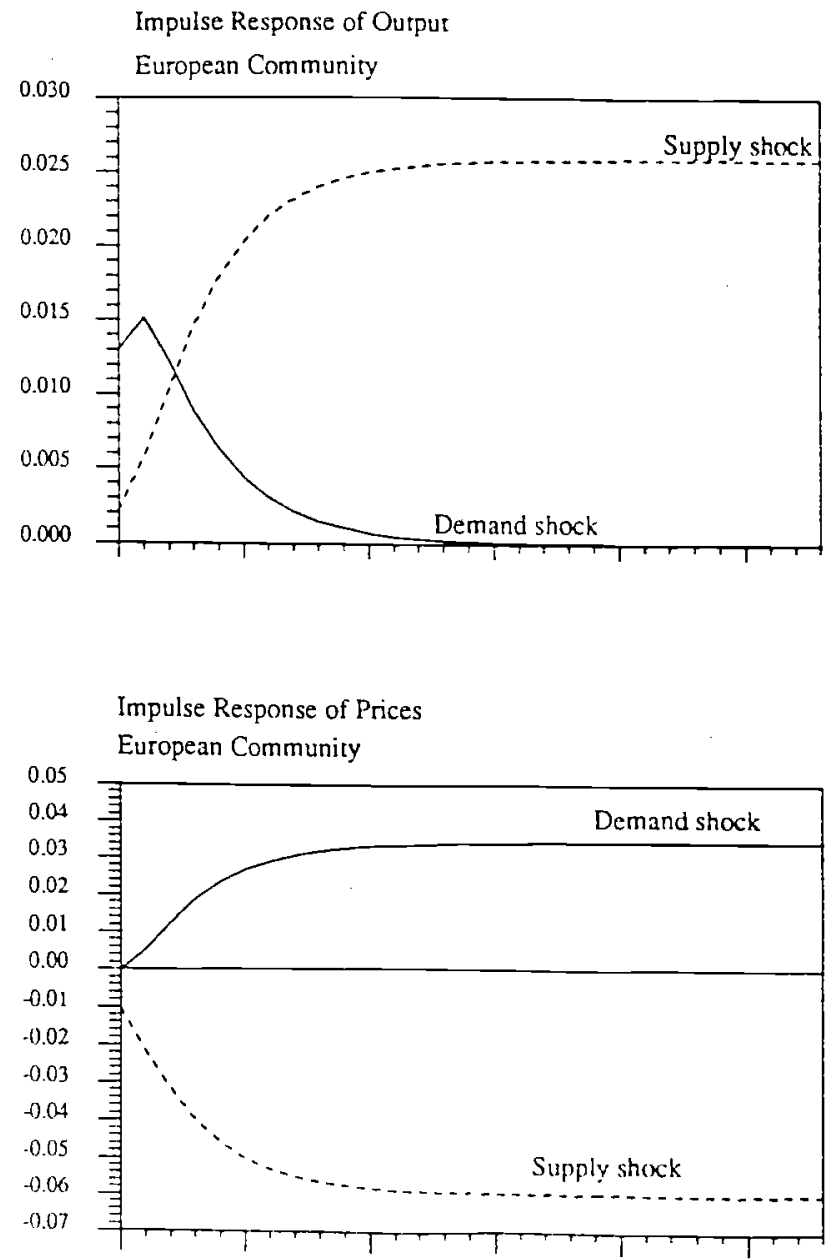


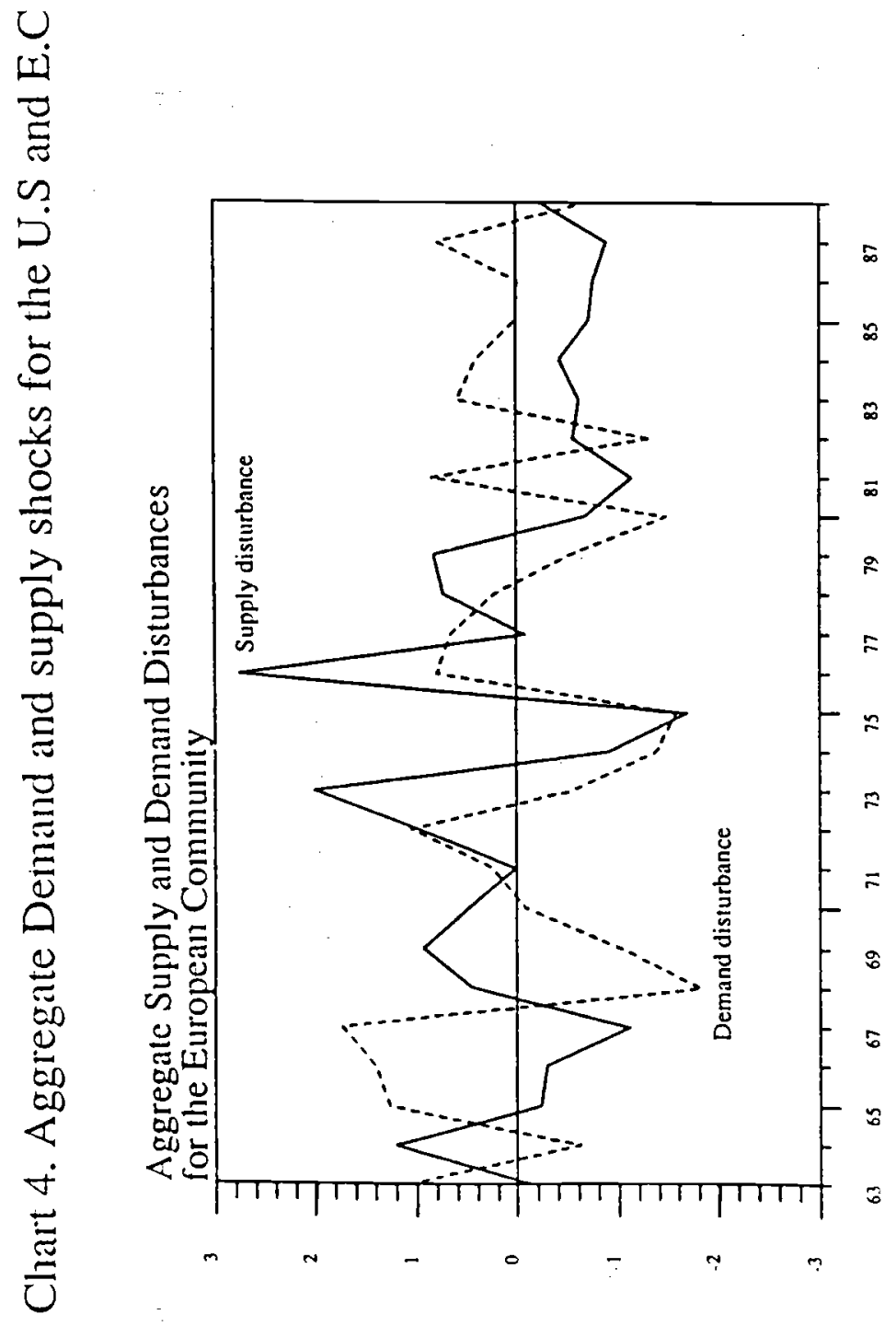


1973-75 and 1979-80, corresponding to the two oil shocks, together with a negative supply shock in 1968 which is more difficult to interpret. The demand disturbances illustrate the different response of the Ec to the first and second oil crises; there is a large positive demand shock in 1977, while from 1980 onwards demand shocks are negative.

Having illustrated the nature of the estimation results, we now use the results to look at the relative performance of the EC core, the EC periphery and EFTA. We look first at the correlation of the underlying disturbances across countries, and then at the size of these shocks. Finally, we compare the spped of adjustment across countries.

\section{Correlations}

A major factor in determining the advantages of joining a common currency area is the correlation of underlying shocks. If shocks are highly symmetric across countries, then the $109 \mathrm{~s}$ of the exchange rate instrument is relatively unimportant, whereas if shocks are highly idiosyncratic the problem of adjustment may be more complicated, justifying different policy responses by different countries. Table 2 summarizes the cross-country correlations of demand and supply shocks for the EC core, the EC periphery and EFTA, again using principal components analysis. Ag in Table 1, the results are reported for the full sample and, to illustrate trends over time, for three successive subperiods.

For the period as a whole both supply and demand shocks are more highly correlated within the EC core than within the EC periphery or EFTA. The values for the EC periphery and EFTA are rather similar. This first bit of evidence suggests, then, that there may be special grounds for an EMU of the core countries not shared by either the EC periphery or EFTA.

When aggregate supply and demand disturbances are estimated separately for successive subperiods, the picture is complicated. The aggregate supply shocks indicate that the performance of the EFTA countries may have been moving away from that of the EC periphery and towards the EC 
Table 2. Percentage of Variance in Supply and Demand Shocks Explained by First Principal component

\begin{tabular}{|c|c|c|c|}
\hline & EC Core & EC Periphery & EFTA \\
\hline \multicolumn{4}{|c|}{ Supply Shocks } \\
\hline Fuli Period & 54 & 32 & 29 \\
\hline $\begin{array}{l}1963-71 \\
1972-79 \\
1980-88\end{array}$ & $\begin{array}{l}39 \\
63 \\
62\end{array}$ & $\begin{array}{l}40 \\
41 \\
41\end{array}$ & $\begin{array}{l}36 \\
49 \\
45\end{array}$ \\
\hline \multicolumn{4}{|c|}{ Demand Shocks } \\
\hline Full Period & 53 & 36 & 36 \\
\hline $\begin{array}{l}1963-71 \\
1972-79 \\
1980-88\end{array}$ & $\begin{array}{l}58 \\
50 \\
54\end{array}$ & $\begin{array}{l}30 \\
49 \\
43\end{array}$ & $\begin{array}{l}44 \\
44 \\
32\end{array}$ \\
\hline
\end{tabular}

Notes: The EC core comprises Germany, France, the Netherlands, Belgium, Denmark and Luxenburg. The EC periphery contains the UK, Italy, spain, Portugal, Ireland and Greece. EFTA/Germany contains Switzerland, Austria, Sweden, Norway, Finland and Iceland 
core. This plaugibly reflects the growth of trade and financial relationg between the leading EC economieg and EFTA. For aggregate demand shocks, the opposite appears to be the case; shocks to EFTA seem to have grown increasingly heterogeneous over time, leading it to more closely resemble the EC periphery. Thig trend in demand shocks may reflect the convergence of EC monetary policieg cauged by the ERM and itg earlier incarnation, the "gnake," in contragt to the floating exchange rate policieg followed by mogt members of EFTA Bince the break-up of the Bretton woods fixed exchange rate regime in the early 19709.18

Thege gummary gtatigticg digguige large divergenceg in behavior among countrieg within each group. Chart 5 digplayg the correlation coefficientg for both demand and supply disturbances between individual EC/EFTA countrieg and Germany. 19 The correlation coefficient for demand ghocks is on the vertical axis, while that for gupply ghocks is on the horizontal axis. Countries clustered near the top, right-hand corner of the box, which exhibit high correlationg with Germany, are prime candidates for joining it in a monetary union. The correlations of aggregate supply disturbanceg are of particular interest, since demand shocks are more likely to reflect government policy and therefore to be endogenoug to the exchange-rate regime.

Belgium, Denmark, France and the Netherlands all have supply disturbanceg which are highly correlated with Germany'g. In addition, their demand digturbances are also reasonably highly correlated with Germany'g. Two EFTA countries -- Austria and Switzerland -- are close behind thege memberg of the EC core in the "race" toward the upper right-

18 More recently, the EFTA countrieg have tended to link their exchange rateg to those of the ERM. Hence as more data become available, this trend may reverse itgelf.

19 Germany is the largegt economy in Europe and has played a leadership role in the ERM, making it the obvious gtandard for comparigon. Here the results for Luxenbourg are not reported, gince it is such a gmall economy. 


\section{Chart 5 - Correlations of the Demand and Supply Disturbances with Germany}

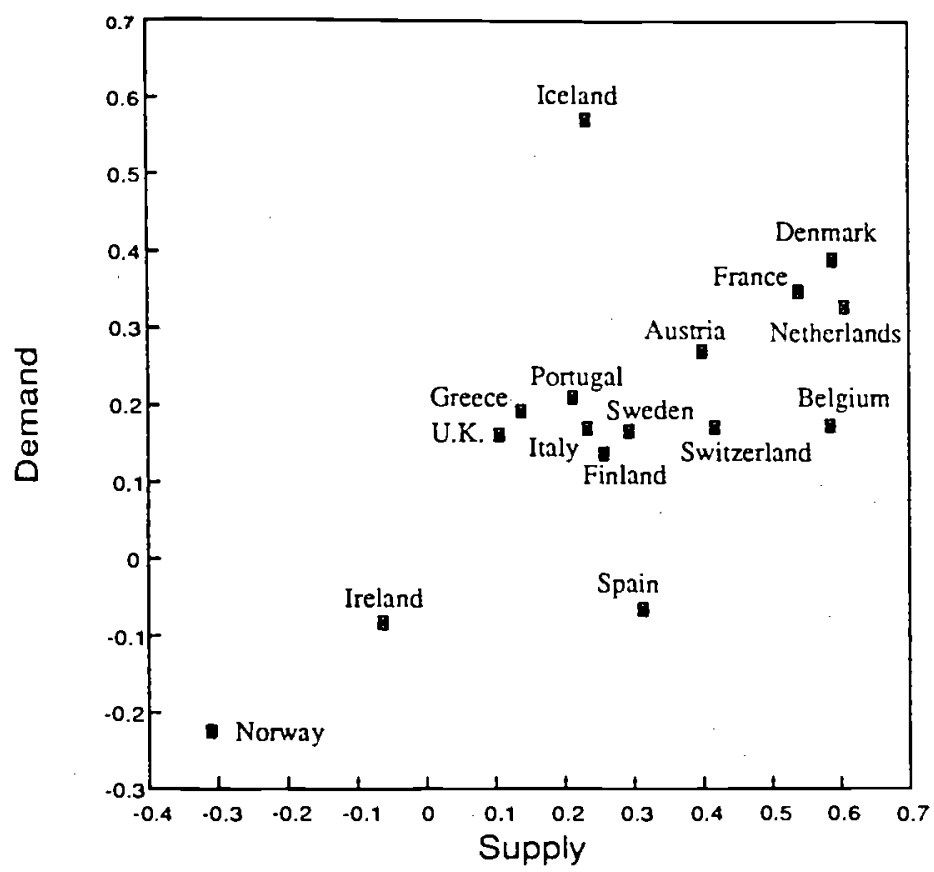


hand part of the box. 20 on the basis of these correlations, Austria and Switzerland would seem to be prime candidates for monetary union.

The other four EFTA members, Sweden, Finland, Iceland and especially Norway, would seem to be less promising candidates for monetary union. Sweden and Finland are in the middle of the sample in terms of the correlation of their disturbances with Germany's. For Norway, the energy producer in our sample, both disturbances are negatively correlated with those of Germany, while in the case of Iceland, the demand disturbances are relatively highly correlated with those of Germany but the supply disturbances are not.

Thus, the cross-country correlation of disturbances creates a stronger presumption in favor of EMU participation for some EFTA countries -- Austria and Switzerland -- than for others -- Sweden, Finland, Norway and Iceland. Still, except for Norway, the case for EMU membership on these grounds is at least as strong as that for such members of the EC periphery as the UK, Greece and spain.

\section{Size of Shocks}

In addition to looking at the symmetry or correlation of shocks across regions, our methodology can be used, as described in section II, to estimate their relative size. 21 The larger the underlying shocks, the more difficult it may be to maintain a fixed exchange rate, and the more compelling may be the case for an independent policy response. This is particularly true of supply shocks, which often require more painful adjustment.

The standard deviations of the aggregate demand and supply

20 A surprising case is Iceland, whose supply disturbances are on 1 y loosely correlated with Germany's, but whose demand disturbances exhibit a high correlation over the sample period.

$21^{2}$ These are calculated using the modification of the VAR decomposition discusged in footnote 10 . 
disturbances are displayed in Chart $6 .^{22}$ Prime candidates for monetary union are countrieg countriea with small disturbances located toward the bottom, left-hand corner of the box. The members of the EC core -Germany, France, Belgium, the Netherlands and Denmark -- are all located near that corner. All have supply ghocks with standard deviations in the range of $0.01-0.02$ (1-2 per cent per annum). In contrast, the standard deviations of the supply shocks for the EC periphery (the U.K., ItalY, Spain, Portugal, Ireland and Greece) range from 0.02 to $0.035(2-31 / 2$ per cent per annum). Thus, as pointed out in Bayoumi and Eichengreen (1991). the peripheral countries experience supply shocks twice as large on average as the core countries.

The patterns exhibited by demand shocks are less coherent. Still, demand shocks to the EC core appear to be distinctly smaller than those experienced by some memberg of the EC periphery, notably Portugal and Ireland.

Three EFTA memberg -- Austria, Sweden and Switzerland -- regide in the same general neighborhood as the members of the EC core. Within this group, Austria and Sweden have particularly low standard deviations. Norway is an interesting case gince while it has relatively small supply disturbances, its demand disturbances are relatively large, making it difficult to clasaify. Finland appears to be located in the EC core, while Iceland has such large underlying disturbances that they have been excluded from the diagram.

Thus, the magnitude of shocks as well as their correlation with Germany's suggest that several EFTA members, namely Austria, Sweden and Switzerland, are good candidates for EMU. Only in the case of Iceland does this part of our analysig give fige to reservations. As with the correlation of disturbances, the magnitude of shocks provides a generally

22 Since the variables are measured in logarithms a standard deviation of (say) 0.012 implies a variation of 1.2 percent. Iceland is again excluded because the standard deviations of its demand any supply shocks, at 0.082 and 0.037 , are so much larger than the other countries in the analyais. 


\section{Chart 6. The Correlation and Size of the Underlying Disturbances}

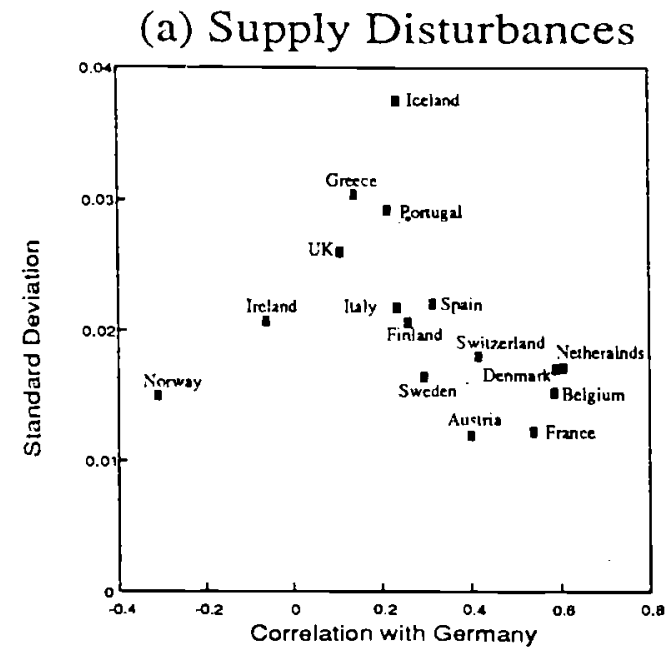

(b) Demand Disturbances

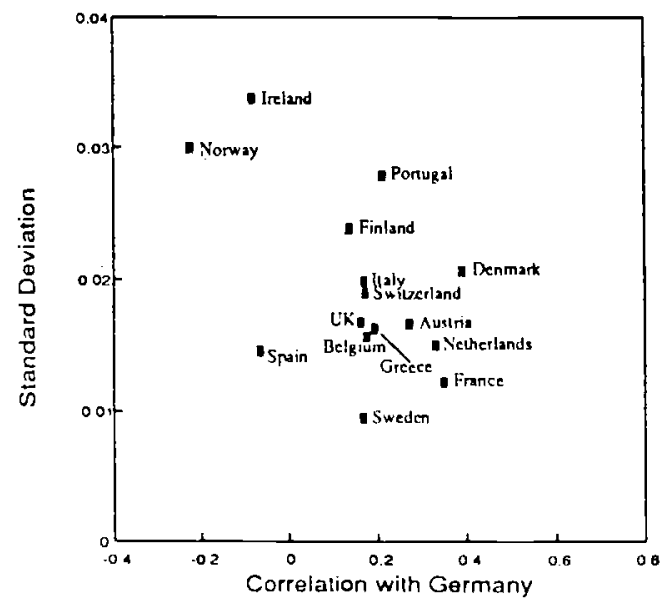


Table 3. The size of the Underlying

Aggregate Supply and Demand Disturbances (Standard Deviationg)

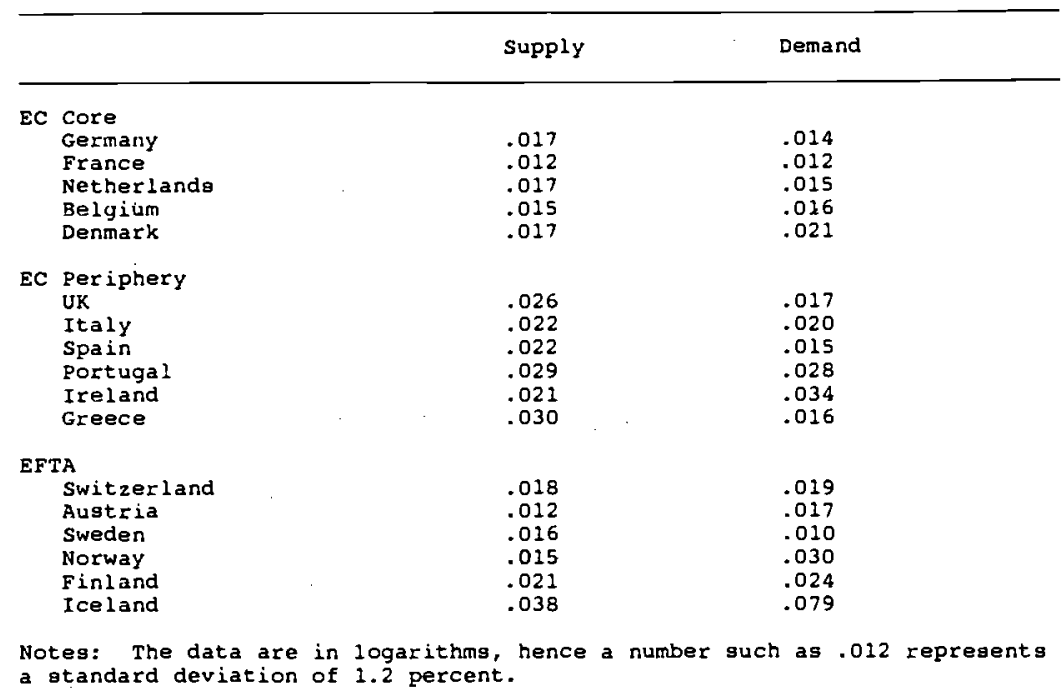


stronger basis for EMU memberghip for the EFTA countries (excluding Iceland) than for the EC periphery, the UK, Italy, spain, Ireland and Portugal.

It is illuminating to contrast the standard deviations of the gupply and demand shocks in chart 6 with the standard deviations of inflation and output growth in chart 2 . When countries are grouped as in Chart 2 according to the variability of inflation and output growth, most EFTA countries appear to form part of the core of the Ec, and thus would be considered ready to enter any monetary union which was formed. When the variability of aggregate supply and demand shocks, as in chart 6 , is taken to measure suitability for entry, as we have argued is more appropriate, the EFTA countries look considerably more mixed, with only Austria and Sweden (the two countries who have formally applied to join the EC) $\mathrm{firmly}$ in the core, switzerland in an intermediate position and Norway and Finland being grouped with the Ec periphery.

\section{Speed of Adjugtment to Shocks}

Our procedure also permits one to compare the reactions of economies to shocks. This can be done by looking at the impulse-response functions associated with the VARs. The slower the speed of adjustment to a given disturbance, the greater the welfare costs. For a given configuration of disturbances, then, countries with particularly slow speed of adjustment, absolutely and relative to countries like Germany certain to participate EMU, are the least plausible candidates for immediate membership.

Chart 7 displays the impulse-response functions for aggregate demand shocks for the EC core, EC periphery and EFTA, respectively, while Chart 8 showg the impulse responsea for aggregate supply shocks. To aid comparison, we have superimposed on each chart the impulse-response function for the EC aggregate.

Chart 7, which shows the response to a demand shock, is simple to interpret: countries with impulse-response functions above and to the right 


\section{Chart 7 - Impulse Response Functions to a Demand shock}
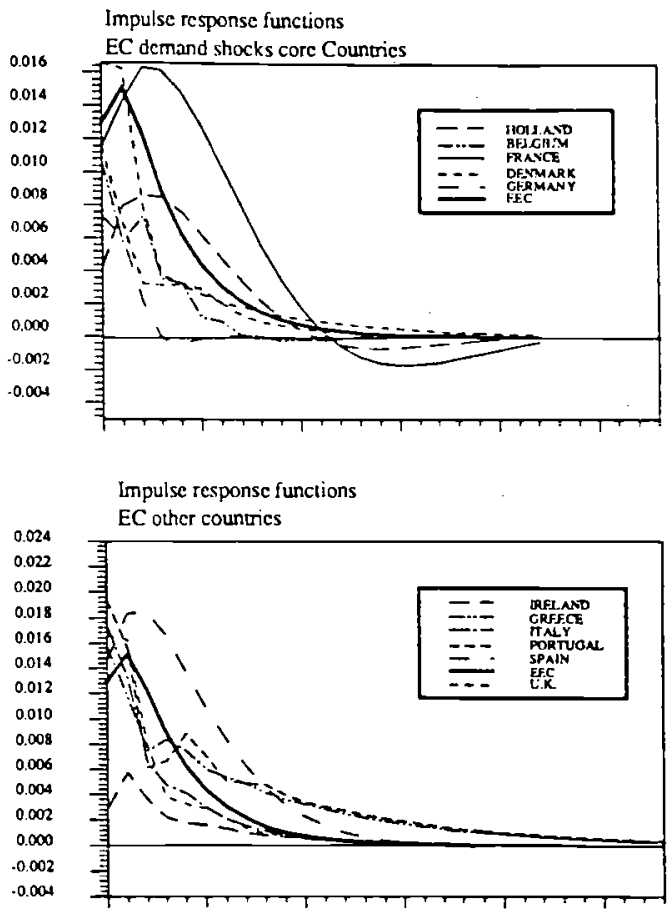

EFTA counuics

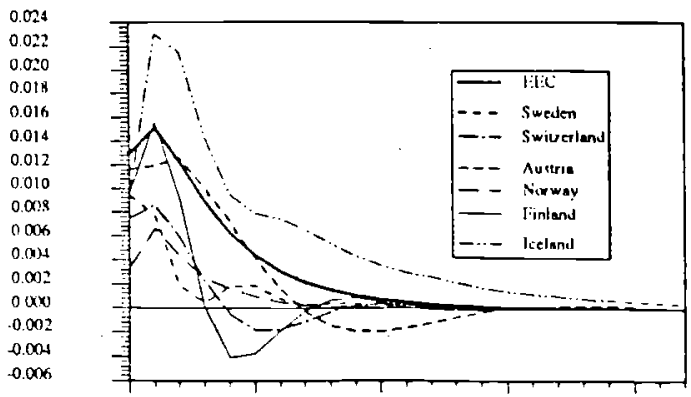




\section{Chart 8 - Impulse response functions Supply shocks}
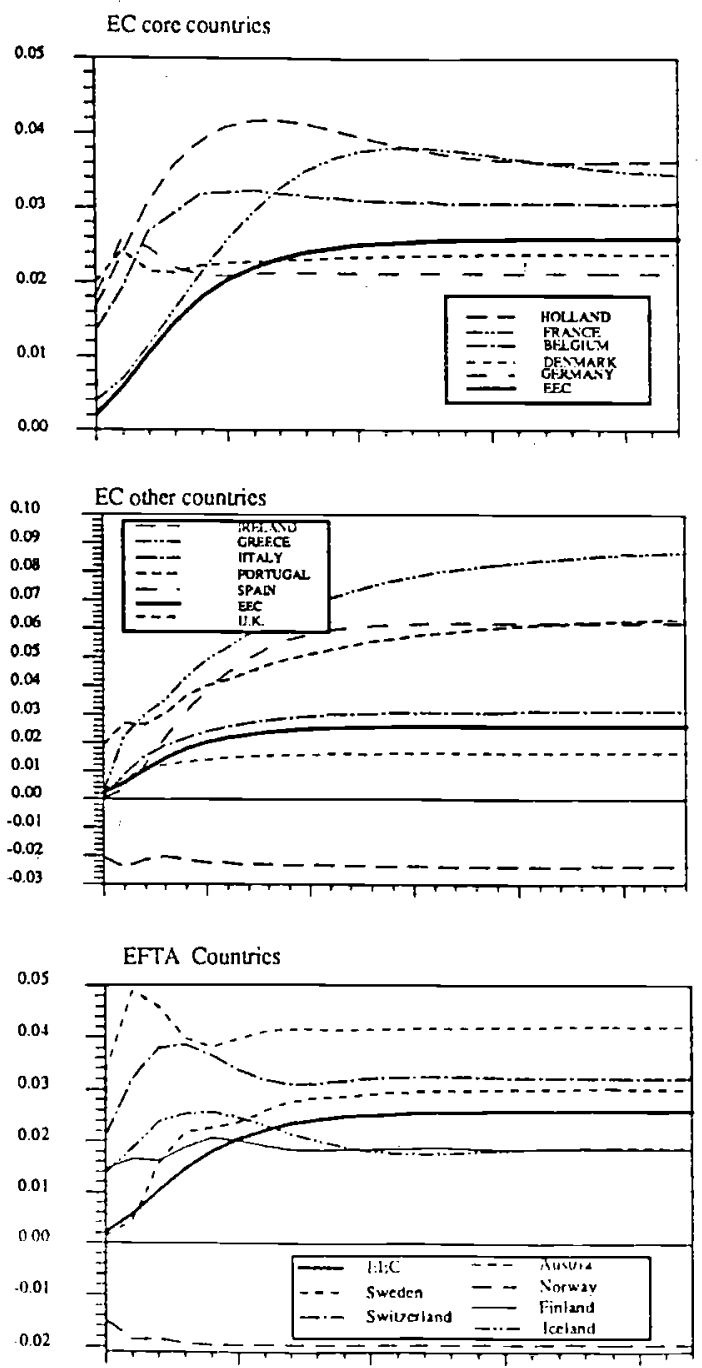
of the aggregate tend to adjust more slowly than average, while countrieg with impulse-reaponge functions below and to the left of the heavy line regpond more quickly. With the exception of France, all of the members of the EC core show relatively fagt responge to demand shocks. The results for the EC periphery are more mixed. While the UK, Italy and Ireland respond slightly faster than the EC aggregate, Greece, Portugal and spain all respond more gluggishly. The responses of the EFTA countries resemble the EC core more clogely than the EC periphery, despite the cycling in the estimated responses of Austria, Finland, and Switzerland. With the exception of Iceland, their impulse-response functions are below those for the EC aggregate, as are mogt of those for the EC core, although the cycling indicates some temporary overshooting when output falls following a positive demand shock, magnifying the transitional costs.

The impulse-response functions for supply shocks must be interpreted differently. In contragt to the case of demand shocks, where output returns ultimately to its initial level, in the case of supply shocks the long-run change in output differs across countries. One measure of speed of adjustment is the ratio of the impulse response of output in the third year to itg long-run level. 23 A high value indicateg relatively East adjustment, a low value relatively slow adjustment. The average value for this statigtic is 0.72 for all EC countries, with the average for the EC core $(0.82)$ being considerably higher than that for the Ec periphery (0.63).24 Ag might be expected from a comparison of chart 8 , in their gpeed of adjustment to supply shocks the EFTA countries more closely resemble the EC core than the EC periphery. Indeed, the average value for EFTA countries $(0.98)$ is actually somewhat larger than for the Ec core.

23 While gomewhat arbitrary, this measure is relatively simple and intuitive. The game calculations, when undertaken for the fifth or seventh year following the shock, pointed to essentialiy the same conclusions.

24 Note that the EC average ig a weighted average of the figureg for the two subgroups, since there are different numbers of countries in the two groups. 


\section{v. Summary and Implicationg}

In this paper we have used structural vector autoregression to identify the incidence of aggregate supply and aggregate demand disturbances in Europe and to analyze the EC economies' response. Central to our analysig is a distinction, emphasized by Bayoumi and Eichengreen (1991), between aggregate supply and demand shocks to the countries at the center of the European Community -- Germany, France, Belgium, the Netherlands and Denmark -- and the very different shocks affecting other Ec memberg. Supply shocks to the EC core are both gignificantly smaller and significantly more correlated across countries. The same is true of demand shocks. There is little evidence of convergence in the sense that this core-periphery distinction is becoming less pronounced over time. Moreover, the core-periphery distinction is reinforced by evidence that the core countries adjugt more quickly to supply and demand disturbances alike. The EFTA countrieg are not readily grouped with either the EC core or the EC periphery. In some respects they more closely resemble the core: this is true, for example, of their speed of response to both aggregate supply and aggregate demand shocks. In other respects they more closely resemble the EC periphery: this is true of the intra-group correlation of both supply and demand shockg. Thig lagt fact -- a low intra-group corralation -- highlights the extent of heterogeneity within EFTA. Some EFTA memberg (Austria, Sweden and Switzerland) display aggregate supply and demand disturbances that are both relatively small and relatively highly correlated with thoge of Germany. Finland and Norway digplay somewhat larger disturbances and, especially in the case of Norway, they are relatively poorly correlated with Germany's, making them more similar to some of the periphery countries in the EC. Finally, Iceland experie nces much larger underlying disturbances than any other country considered in the sample.

What are the implications of the findings reported in this paper for the debate over monetary union? Advocates of two-speed EMU will derive 
gome comfort from our finding of a clear distinction between an $5 c$ core and an EC periphery, although the information reported here is obviously not sufficient to make or break their case. Those who believe that all 11 Ec members can proceed rapidly toward completion of EMU will be reassured to learn that enlargement of the community to include the EFTA countries does not pose an obvious challenge to their position. The EFTA countries ag a whole exhibit behavior midway between that of the Ec core and that of the EC periphery. If the U.K., Italy, Greece, Spain and portugal are gualified to join the EMU, so too, judged in terms of the disturbances they experience and their capacity to respond, are Austria, Finland, Iceland, Norway, Sweden and Switzerland.

In a sense, however, our analysis suggests that the Ec core, the EC periphery and EFTA are not the relevant categories for discussions of EMU membership. EFTA is more logically divided into two subgroups: Austria, Sweden and Switzerland belong with the EC core, while the same is not clearly true of Norway, Iceland and Finland. If the Ec proceeds with twospeed EMU, this suggests, one should expect to see more vehicles in both the fast and slow lanes. 


\section{REFERENCES}

Bayoumi, Tamin (1991), "The Effects of the ERM on Participating Economies," IME WP/91/86.

Bayoumi, Tamim and Barry Eichengreen (1991), "Shocking Aspects of European Monetary Unification," unpublished manuscript, International Monetary Fund and University of California at Berkeley.

Bayoumi, Tamim and Massimo Russo (1991), "Fiscal Policy and EmU," paper pregented at the conference on "European Economic and Monetary union," Barcelona, 1-5 July.

Blanchard, Olivier and Danny Quah (1989), "The Dynamic Effects of Aggregate Demand and Supply Disturbances," American Economic Review 79, pp.655-673.

Dornbusch, Rudiger (1990), "Two-Track EMU, Now!" in Korl otto Pohl et al., Britain and EMU, London: Centre for Economic Performance, pp.103-112.

Dornbusch, Rudiger and Stanley Fischer (1986), Macroeconomics, New York: McGraw Hill, third edition.

Eichengreen, Barry (1991), "Is Europe an optimum Currency Area?" CEPR Discusgion Paper No. 478, forthcoming in Herbert Grubel (ed.), European Economic Integration: The View from Outside (London: Macmillan).

Economist Magazine (1991), "Finland: Europe Aho," 14-20 September, pp.5657.

Goldgtein, Morris and G. Woglom (1991), "Market-Baged Fiscal Digcipline in Monetary Unions: Evidence from the U.S. Municipal Bond Market," unpublished manuscript. International Monetary Fund.

Gylfason, Thorvaldur (1990), "Iceland on the Outskirts of Europe: The Common Property Resource Próblem," in EFTA (ed.), EFTA Countries in a Changing Europe, Geneva: EFTA, pp.81-95.

Hall, Robert and John Taylor (1988), Macroeconomics: Theory, Practice and Policy, New York: McGraw Hill, third edition.

Hamilton, Carl B. (1990), "The Nordic EFTA Countrieg' Options: Community member or a Permanent EEA Accord," in EFTA (ed.), EFTA Countrieg in a Changing Europe, Geneva: EFTA, pp.97-127.

Lippi, M. and L. Reichlin (1990), "A Note on Measuring the Dynamic Effects of Aggregate Demand and Supply Disturbances," unpublished manuscript.

Lodge, Ian (1991), "Big Step Towards Full EC Membership," Financial Timeg, 9 october, p.s.2.

Mundel1, Robert (1961), "A Theory of Optimum Currency Areag," American Economic Review, pp.657-665.

Quah, Danny (1991) "Identifying Vector Autoregressions. A Discusgion of $P$. Englund, A. Vredin and A Warne: Macroeconomic Shocks in Sweden 1925-86", unpublished manuscript, London School of Economics, September.

Sims, Chrigtopher (1980), "Macroeconomics and Reality," Econometrica 48, pp. 1-49. 